\title{
Avoiding emergency stops in end of life care
}

\author{
Fiona Hicks
}

'Death must be distinguished from dying, with which it is often confounded.' Revd Sydney Smith. ${ }^{1}$

We have all seen her. Many of us see her several times in a week, although her name may have changed. She lies in bed in a hospital nightdress, old, pale, thin or fat, quiet or talkative, sharp as a tack or quite 'confused'. She reached her prime many years ago (or perhaps last week). We do not see her hopes, fears, achievements, memories, loves or losses. We see her chest X-ray, ECG, FBC, U\&Es and LFTs. We clerk her on the admissions proforma, note her next of kin, treat her pneumonia according to our antibiotic guidelines, assess her risk for VTE, manage her heart failure, monitor her renal impairment, note her long list of medications and struggle to find her a bed.

She is coming to the end of her life. She is dying, but she isn't dead. She is alive to new experience: to pain, to hope, to fear.

And here is our challenge. Do we look up from the immediate need, the 'presenting complaint', and see the person within the failing body? Do we even recognise that she is dying - maybe not this time, but soon? Do we ask her what she hopes for - or expects - from our treatment? Do we wonder if she knows she is dying - maybe over weeks, months or years?

Much of medical training and practice is about filtering information to focus on the pathology. We are trained to look past social status, age and background impartially to seek out the medical problems and to treat with an aim to cure. Time is pressing and, if we're honest, there are occasions when we simply treat the condition and move on. The approach has been remarkably effective.

In his beautifully written foreword to the NCEPOD Report, Caring to the end?, Professor Treasure notes that 'Modern medicine has been hugely successful in blocking one after another of the too early routes of exit but, perhaps partly as a consequence of being able to postpone the inevitable so successfully in so many instances, a timely death remains difficult to discuss and therefore perhaps less well managed than it might be.' ${ }^{2}$

Life expectancy has increased. Paradoxically, improved longevity is leading to a more protracted period of dying, as acute deaths are less common and the number of people living with, and dying from, long-term conditions is increasing. This begs the question - 'How can we establish a 'timely' death?' Or to put it another way - how can good care at the end of life be defined and delivered?

Modern medicine has created systems designed to intervene and to treat illness. Partly as a consequence we have moved care

Fiona Hicks, consultant in palliative medicine, Leeds Teaching Hospitals Trust; senior clinical lead for end-of-life care, Yorkshire and the Humber Strategic Health Authority from home into hospitals, where patients enter a system of diagnosis and treatment. Currently in the UK, around $1 \%$ of the population, or 600,000 people, die every year. More than half of these die in hospital. ${ }^{3}$ With the final stages of life frequently characterised by an increasing dependence on those around the person, sometimes over months or years, this creates an increased dependency on medical practitioners and an increased reliance on doctors to provide the conditions for a 'good' death. The 2008 National End of Life Care Strategy highlighted that, when asked, most people would prefer to die at home. ${ }^{4}$ Perversely, the structure of our health service and patient expectations of modern medicine dictate that hospital admission is now the norm. Many people have multiple admissions to hospital in the last year of life, ${ }^{5}$ so it is all too easy for the dying person to become a 'patient' and lose control over their life at what is a most critical stage.

Age Concern's 'Twelve principles of a good death' (Box 1) offers a considered foundation for end-of-life care and calls for an equally considered response.

Care of the dying has received a lot of attention in recent years, including the introduction of the Liverpool Care Pathway for the Dying (LCP), or its equivalent, to most hospitals in the UK. ${ }^{6}$ However, we must not interpret the LCP, with its improved care in the last hours or days of life, as a total care-of-the-dying package. If we are to aspire to the 'Twelve principles', we face a

Box 1. Age Concernís Twelve principles of a ëgood deathi..$^{10}$

- To know when death is coming, and to understand what can be expected

- To be able to retain control of what happens

- To be afforded dignity and privacy

- To have control over pain relief and other symptom control

- To have choice and control over where death occurs (at home or elsewhere)

- To have access to information and expertise of whatever kind is necessary

- To have access to any spiritual or emotional support required

- To have access to hospice care in any location, not only in hospital

- To have control over who is present and who shares the end

- To be able to issue advance directives which ensure wishes are respected

- To have time to say goodbye, and control over other aspects of timing

- To be able to leave when it is time to go, and not to have life prolonged pointlessly 
much bigger challenge - to recognize that, for most people, dying begins months or years before death.

Does talking of death speed its approach? The difficulty that can be experienced in talking with a patient about their end of life might lead one to think this was the case. Of course, this is a societal issue, rather than one limited to medicine, but that does not exonerate physicians from our duty of care. There is a lack of preparation of junior doctors for their role in caring for dying patients. ${ }^{7}$ Significant numbers of doctors perceive their own failure in the death of a patient, and good practice in endstage care continues to be subject to significant regional variation. ${ }^{8}$ Dealing with dying is clearly a challenge and an area of practice that many in the profession find difficult. As doctors we need to reassess what is important in the delivery of care in the last phase of life, challenge society's norms and expectations and train ourselves and our colleagues - both junior and senior - to equip them to recognise and accept that dying is a vital part of living.

Talking with patients about their dying can be uncomfortable and waiting for the 'right time' or choosing the appropriate environment is an effective avoidance strategy, especially in busy hospital practice. Many of us feel that we don't have the necessary skills and fear embarrassment, misunderstanding, complaints, anger or tears. In our discomfort it's easy to turn to jargon, euphemism or other evasion, and to procrastinate over the simplest discussion. Life experience teaches us that early, small adjustments are almost always preferred to sudden, sizeable interventions. Our driving instructor demands good awareness and subtle use of controls to prevent an emergency stop or worse. Similarly, many of the events that occur during the last phases of life are known and can be anticipated. Our experience means that early, small interventions may be made that preempt later sudden changes in approach and expectations, and allow people the time to make choices about their treatment and care. Open communication is fundamental to this.

Recognising that clinical leadership is pivotal, a joint working party of the RCP, the Association for Palliative Medicine and the National End of Life Care Programme has been considering the role of physicians and organisations in improving care for people coming to the end of their lives. Published this month, Improving End of Life Care; Professional Development for Physicians outlines physicians' views on their training, continuing development and practice in end-of-life care. ${ }^{9}$ Notable findings include the lack of formal postgraduate education in this area, coupled with a high frequency of such patient contacts. Confidence in this area of practice was reported as high in an online questionnaire, but focus groups and telephone interviews gave a more indepth and mixed picture, with areas of considerable professional and personal uncertainty. A key theme is that we work within a culture and with systems that do not facilitate this area of practice until death is imminent. Discontinuity in care between shifts, teams and organisations all too often leads to ill-considered and sometimes ill-advised treatment. Personal, experiential learning was thought to be most profound, whether this came from shadowing experienced colleagues, placements with palliative care teams and services, or personal experiences good or bad - of the care of loved ones at the end of life. The report includes practical recommendations to help physicians consider ways to make a positive impact on the care of their patients towards the end of their lives. Thoughtful consideration of its recommendations and judicious use of tools that could modify the systems we use could have a major impact on this important part of our work. With the death rate due to rise from this year onwards, good end-of-life care has never been more important. It is no longer feasible, and neither is it desirable, to maintain the status quo.

\section{References}

1 Lady Holland. A Memoir of the Reverend Sydney Smith. Longman, Brown, Green, and Longmans, 1855.

2 National Confidential Enquiry into Patient Outcome and Death. Deaths in acute hospitals: Caring to the end? London: NCEPOD 2009. www.ncepod.org.uk/2009dah.htm [Accessed 30 January 2012].

3 National End of Life Care Intelligence Network. End of life care profiles: place of death. NEoLCIN, 2009. www.endoflifecareintelligence.org.uk/profiles/2/Place_of_Death/atlas.html [Accessed 30 January 2012].

4 Department of Health. End of Life Care Strategy: promoting high quality care for all adults at the end of life. London: DH, 2008.

5 Lyons P. Pattern of hospital admissions in the final year of life. In: International Society of Advance Care Planning and End of Life Care Conference, 22-24 June 2011, London, UK.

6 Marie Curie Palliative Care Institute. Liverpool Care Pathway for the Dying Patient (LCP). www.mcpcil.org.uk/liverpool-carepathway/index.htm [accessed 30/01/2012].

7 Gibbins J, McCoubrie R, Forbes K. Why are newly qualified doctors unprepared to care for patients at the end of life? Med Educ 2011;45:389-99.

8 Royal College of Physicians. Palliative care services, meeting the needs of patients. Report of a working party. London: RCP, 2007.

9 Royal College of Physicians. Improving End of Life Care: Professional Development for Physicians. Report of a working party. London: RCP, 2012.

10 Age Concern. Debate of the Age Health and Care Study Group. The future of health and care of older people: the best is yet to come. London: Age Concern [formerly Age UK], 1999.

Address for correspondence: Dr Fiona Hicks, Palliative Care Team Office, Robert Ogden Centre, St James' University Hospital, Beckett Street, Leeds LS9 7TF.

Email: Fiona.Hicks@leedsth.nhs.uk 